Case Report

\title{
A tale of traumatic diaphragmatic hernia
}

\section{Indrajit Anandakannan*, Shanthi Ponnandai Swaminathan, Vikas Kawarat, Rajeshwari Mani, Arul Kumar Chinnappan, Kannan R.}

Institute of General Surgery, Madras Medical College and Rajiv Gandhi Government General Hospital, Chennai, Tamil Nadu, India

Received: 25 October 2020

Accepted: 12 November 2020

\section{*Correspondence:}

Dr. Indrajit Anandakannan,

E-mail: gijohokbiack@gmail.com

Copyright: (c) the author(s), publisher and licensee Medip Academy. This is an open-access article distributed under the terms of the Creative Commons Attribution Non-Commercial License, which permits unrestricted non-commercial use, distribution, and reproduction in any medium, provided the original work is properly cited.

\begin{abstract}
A traumatic diaphragmatic hernia is uncommon which accounts for 0.8 to $1.6 \%$. In Blunt or penetrating abdominal injury, the patient presents as early or delayed respiratory distress or intestinal obstruction. We present the 55-year old female with a road traffic accident (pedestrian versus two-wheeler) with left-sided chest pain and breathlessness, left shoulder and leg pain referred to our institute. On examination, left hemithorax decreased breath sound and bowel sound was present, chest compression test positive, normal bowel sound in the abdomen, restricted left shoulder movement and abnormal mobility of shaft of left tibia and fibula. A plain X-ray of the chest and abdomen showed bowel shadow in the left hemithorax up to the apex. Computed tomography (CT) of thorax and abdomen shows herniation of stomach, transverse colon, omentum in the left hemithorax with collapsed left lung. A plain X-ray of the left shoulder shows neck of scapula fracture, left leg both bone fracture. Suggesting traumatic diaphragmatic hernia took emergency surgery, laparotomy was made intact stomach, transverse colon, omentum reduced with no injuries, radially placed diaphragmatic rent of size $10 \mathrm{~cm} \times 5.5 \mathrm{~cm}$ through which left lung inferior lobe visualized, medial edge of rent close to the pericardial pad of fat. Other solid organs normal, left thoracic drain was fashioned. Rent was closed with interrupted polypropylene with intraabdominal drain. Left leg both bone fracture was done with tibial nailing and left neck of scapula fracture managed conservatively. Abdominal approach is sufficient rather than a thoracoabdominal approach given associated intraabdominal injuries, nowadays minimal access approaches preferred.
\end{abstract}

Keywords: Trauma, Emergency medicine, Pneumothorax, Traumatic diaphragmatic hernia

\section{INTRODUCTION}

Diaphragmatic injuries were described by Sennertus in 1541. Riolfi has done first successful repair in 1886. A traumatic diaphragmatic hernia is uncommon which accounts for 0.8 to $1.6 \% .^{1}$ In Blunt or penetrating abdominal injury, the patient presents as early or delayed respiratory distress or obstruction. ${ }^{2}$ Respiratory distress mainly due to pneumothorax or hemothorax, herniation of intra-abdominal organs and injury to the lung parenchyma. Abdominal pain due to strangulation of hernial content can occur earlier but mostly delayed presentation. The mortality mainly confides on associated injuries.
Diagnosing the condition is high suspicion even with investigation modalities available. Surgery is the mainstay of treatment.

\section{CASE REPORT}

We report a case of a 55-year female with a road traffic accident (pedestrian versus two-wheeler) with left-sided chest pain and breathlessness, left shoulder and leg pain referred to our institute. In emergency department on examination, her vitals were stable, left hemithorax decreased breath sound and bowel sound was present, chest compression test positive, normal bowel sound in the 
abdomen, restricted left shoulder movement and abnormal mobility of shaft of left tibia and fibula.

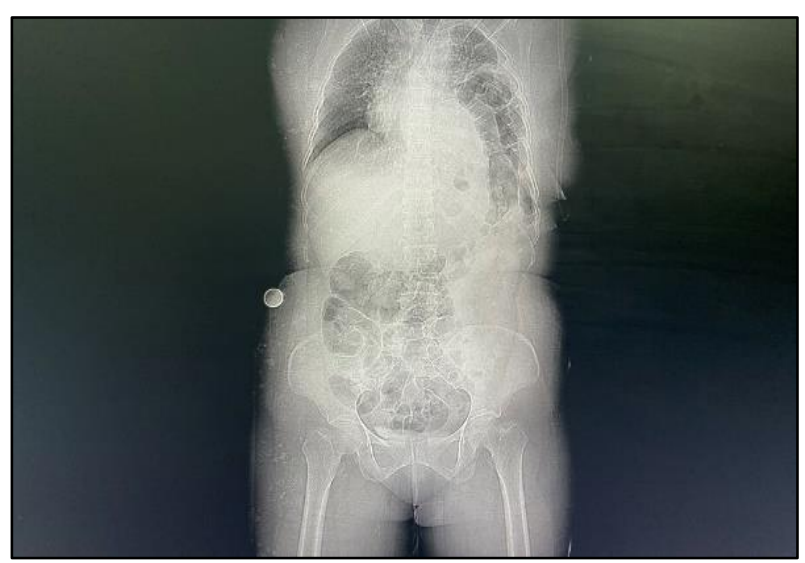

Figure 1: A plain x-ray of the chest and abdomen shows bowel shadow in the left hemithorax up to the apex.

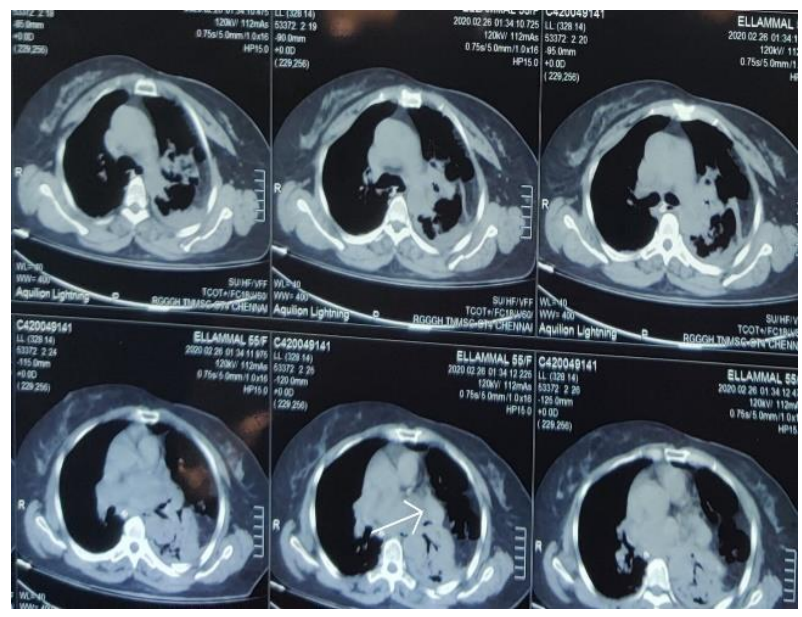

Figure 2: CT of thorax shows herniation bowel in the left hemithorax with collapsed left lung (white arrow).

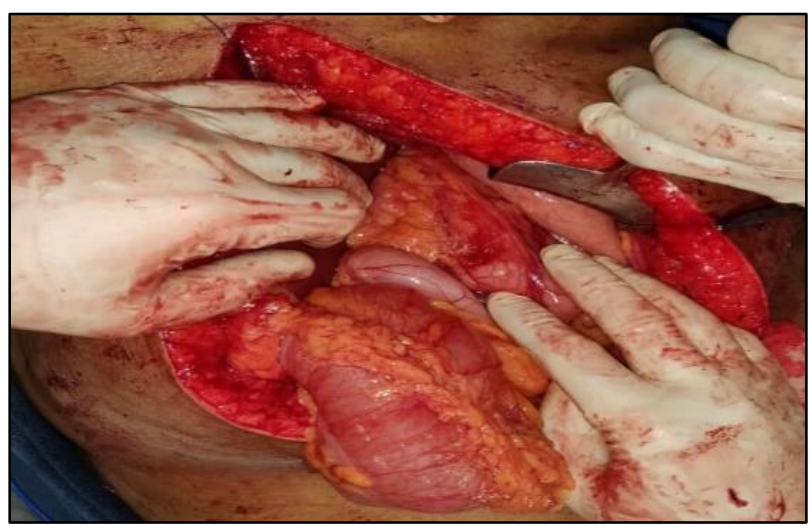

Figure 3: Herniated intact intra-abdominal content reduced.

A plain X-ray of the chest and abdomen showed bowel shadow in the left hemithorax up to the apex. (Figure 1)
After stabilization Computed tomography (CT) of thorax and abdomen was taken which shows herniation of stomach, transverse colon, omentum in the left hemithorax with collapsed left lung (Figure 2). A plain X-ray of the left neck of scapula shows fracture and left leg both bone fracture.

Her echocardiogram shows stable cardiac status. Suggesting of traumatic diaphragmatic hernia, the patient was taken for emergency surgery after informed high-risk consent laparotomy was made intact stomach, transverse colon, omentum reduced with no injuries. (Figure 3)

Radially placed diaphragmatic rent of size $10 \mathrm{~cm}$ x $5.5 \mathrm{~cm}$ through which left lung inferior lobe visualized, (Figure 4) where the medial edge of rent close to the pericardial pad of fat, other solid organs normal (liver, spleen), left thoracic drain was fashioned with underwater seal drainage. Rent was closed with interrupted polypropylene (Figure 5) and intraabdominal drain fashioned. Left leg both bone fracture was done with tibial nailing and left neck of scapula fracture managed conservatively.

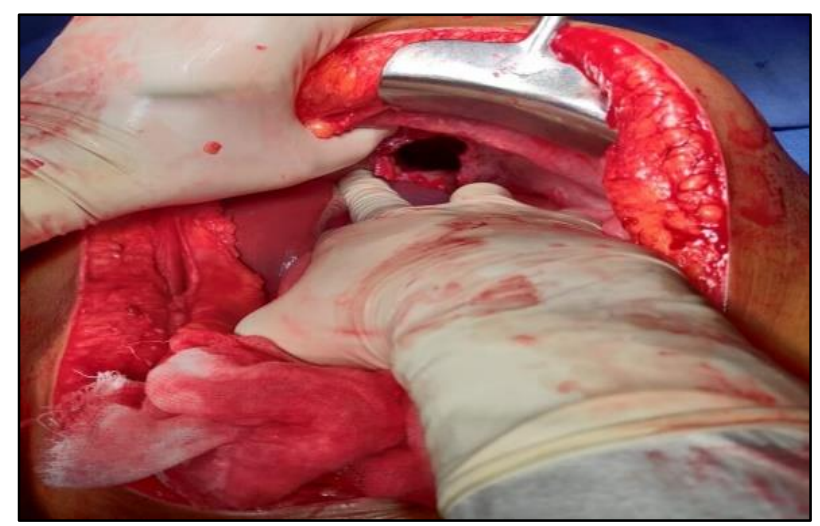

Figure 4: Intra-operative field depict diaphragmatic rent.

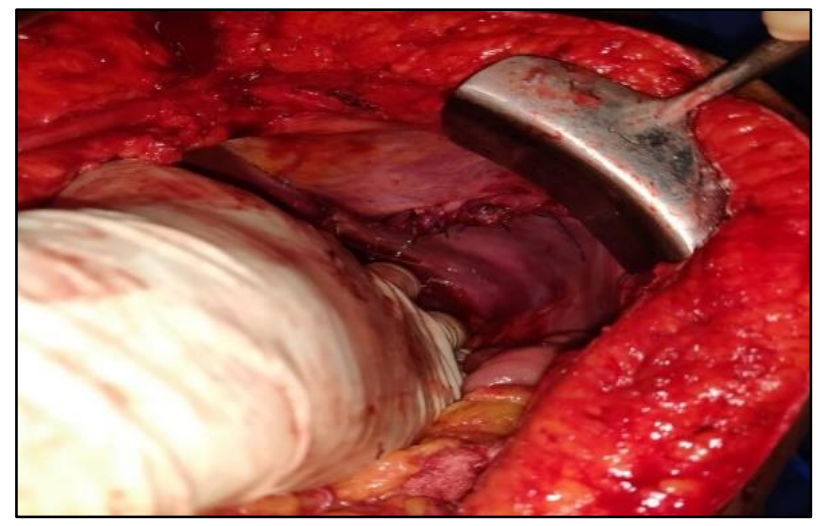

Figure 5: Rent closed with interrupted polypropylene suture.

The patient recovered well and discharged on a postoperative day 13 . 
Reviewed after 4 weeks, she had no complaints and able to do routine activities without any discomfort.

\section{DISCUSSION}

Traumatic diaphragmatic hernia is mainly due to blunt or penetrating injuries to the abdomen depending on the velocity of injury. The left side of the chest is commonly affected than the right side because of the protective effect by the liver. ${ }^{3}$

They may present as chest pain, dyspnea in an acute setting due to pneumothorax, on examination decreased air entry, the condition when air leaks into space between lung and chest wall due to blunt or penetrating chest injury or present late due to the magnitude of other multiorgan injuries as hemothorax, pneumonia, sepsis, deep vein thrombosis. $^{4}$

Mechanism of injury is due to an increase in intraabdominal pressure as a result of trauma, shearing and avulsion. The positive pressure gradient between the intraperitoneal and intrapleural cavity of 7-20 cm H2O forces the abdominal content into the thorax, with severe trauma the pressure gradient may raise to $100 \mathrm{~cm} \mathrm{H} 2 \mathrm{O}^{5,6}$

American association for the surgery of trauma (AAST) classified diaphragmatic injury scale as Grade 1 contusion, Grade 2 laceration $<2 \mathrm{~cm}$. Grade 3 laceration $2-10 \mathrm{~cm}$, Grade 4 laceration $>10 \mathrm{~cm}$ with tissue loss $<25 \mathrm{~cm}^{2}$, Grade 5 laceration with tissue loss $>25 \mathrm{~cm}^{2}$.

Grimes proposed diaphragmatic rupture in 3 phases: acute phase patients with polytrauma (multiple intraabdominal and chest injuries), latent phase undetected diaphragmatic rupture or rent where herniation occurs, obstructive phase where herniated loop got obstructed. ${ }^{8}$

High clinical index of suspicion is needed to diagnose and effectively manage diaphragmatic rupture even with a remote history of high-velocity injury. A plain chest x-ray may show the nasogastric tube in the chest and bowel gas shadow in the chest with the elevation of hemidiaphragm (collar sign), CT thorax shows the elevation of hemidiaphragm $>4 \mathrm{~cm}$ on the affected side with the abdominal content, with contrast, increased sensitivity and specificity in visualizing content and rupture if any. ${ }^{9}$ Focused assessment sonography in trauma (FAST) can be used in diagnosing diaphragmatic hernia. ${ }^{10}$ However, in the absence of hernia, it may be difficult to identify diaphragmatic injury by conventional imaging.

We managed this case by laparotomy and reduction of content followed by a thorough examination for injuries. Small rent in the diaphragm can be managed with simple suturing with non-absorbable material, large defects may require mesh fixation. ${ }^{11}$ Laparotomy is superior to thoraco laparotomy in the case of polytrauma as there could be associated with intraabdominal injuries. Laparotomy should be preferred in unstable patients.

\section{CONCLUSION}

This patient referred from other centres without ICD insertion despite suspected pneumothorax, where insertion of ICD could have been harmful rather than beneficial in this case. Abdominal approach is sufficient rather than a thoracoabdominal approach given associated intraabdominal injuries. A smaller diaphragmatic defect can be closed with interrupted non-absorbable suture as carried out in this case. Larger defects are managed mesh superimposition after primary closure. Nowadays minimal access approaches preferred.

\section{ACKNOWLEDGEMENTS}

Under the guidance of chief Prof Dr P. S. Shanthi, Primary data collection and compilation did by Indrajit Anandakannan surgery resident, with the help of assistant professors' Dr Vikas, Dr Rajeshwari and surgery resident Dr Arul Kumar Chinnappan. With the support of the director of our Institute Dr Kannan.

\section{Funding: No funding sources \\ Conflict of interest: None declared \\ Ethical approval: Not required}

\section{REFERENCES}

1. Lal S, Kailasia Y, Chouhan S, Gaharwar A, Shrivastava G. Delayed presentation of posttraumatic diaphragmatic hernia. 2020.

2. D, Farboud A, Luckraz H. A review diaphragmatic injury. Respiratory Medicine CME. 2009;2(1):1-6

3. Zarour A, El-Menyar A, Al-Thani H, Scalea T, Chiu W. Presentations and outcomes in patients with the traumatic diaphragmatic injury. Journal of Trauma and Acute Care Surgery. 2013;74(6):1392-98.

4. Fair K, Gordon N, Barbosa R, Rowell S, Watters J, Schreiber M. Traumatic diaphragmatic injury in the American College of Surgeons National Trauma Data Bank: a new examination of a rare diagnosis. The American Journal of Surgery. 2015;209(5):86469.

5. Iadicola D, Branca M, Lupo M, Grutta E, Mandalà S, Cocorullo G, et al. Double traumatic diaphragmatic injury: A case report. International Journal of Surgery Case Reports. 2019;61:82-85.

6. Ala-Kulju K, Verkkala K, Ketonen P, Harjola P. Traumatic rupture of the right hemidiaphragm. Scandinavian Journal of Thoracic and Cardiovascular Surgery. 1986;20(2):109-14.

7. Moore E, Malangoni M, Cogbill T, Shackford S, Champion H, Jurkovich $\mathrm{G}$ et al. ORGAN INJURY SCALING IV. The Journal of Trauma: Injury, Infection, and Critical Care. 1994;36(3):299-300.

8. Grimes O. Traumatic injuries of the diaphragm. The American Journal of Surgery. 1974;128(2):175-81.

9. Sliker C. Imaging of Diaphragm Injuries. Radiologic Clinics of North America. 2006;44(2):199-211. 
10. Hawkins M, Blaivas M, Brannam L, Lyon M, Sriram K. Bedside Emergency Ultrasonographic Diagnosis of Diaphragmatic Rupture in Blunt Abdominal Trauma. Southern Medical Journal. 2003;96:40-1.

11. Hanna W, Ferri L, Fata P, Razek T, Mulder D. The Current Status of Traumatic Diaphragmatic Injury: Lessons Learned From 105 Patients Over 13 Years. Ann Thorac Surg. 2008;85(3):1044-8.
Cite this article as: Anandakannan I, Swaminathan SP, Kawarat V, Mani KR, Chinnappan AK, Kannan R. A tale of- traumatic diaphragmatic hernia. Int Surg J 2021;8:420-3. 